\title{
Using Knowledge Management to Improve Transparency in E-voting
}

\author{
Alexandros Xenakis and Ann Macintosh \\ International Teledemocracy Centre, Napier University \\ 10 Colinton Road, Edinburgh, EH10 5DT, UK \\ Telephone: +44 (0) 1314552545 Fax: +44 (0) 1314552282 \\ www.teledemocracy.org \\ \{a.xenakis, a.macintosh\}@napier.ac.uk
}

\begin{abstract}
In this paper we argue that knowledge management is required to improve transparency in e-government processes and to support their social acceptance. We present the main information flows and knowledge management issues identified in the case of the UK Local Authority elections $2^{\text {nd }}$ May 2002 electronic voting pilots. We provide a comprehensive view of the major areas of information flows either provided to or produced by the main agents (namely voters, administration staff, local authorities and commercial suppliers) involved in the projects. In doing so we highlight the issues of security, data protection, and transparency of information flows and their relation to the social acceptance of electronically services elections.
\end{abstract}

\section{Introduction}

This paper was produced as part of a doctoral research program exploring the use of business process re-engineering (BPR) methodologies to provide management, modeling and analysis methods for electronic voting.

In August 2002 the UK government issued a consultation paper on a policy for electronic democracy [HM Government, 2002]. This consultation document usefully argues that e-democracy can be divided into two distinct areas - one addressing eengagement and the other addressing e-voting. In the case of latter the paper argues that e-voting should be viewed as a technological problem. In the case of the former, the document sets out the possibilities for greater opportunity for consultation and dialogue between government and citizens. One of the actions taken to promote new methods of voting was to conduct 30 voting pilot schemes in the $2^{\text {nd }}$ May 2002 Local Authority Elections. The pilots were funded by the DTLR (Department of Transport Local Government Regions) and approved by the Electoral Commission [Modernizing elections, Electoral Commission 2002]. Out of 30 pilot schemes, 16 were concerned with e-voting applications. All 16 local authorities used electronic counting schemes -7 of which combined with traditional paper ballots only, 6 provided e-voting in the form of touch-screen voting kiosks, 5 provided internet voting, 3 provided phone (touch tone) voting and 2 SMS text message voting [Pratchett 2002]. This paper identifies the main knowledge and information flows within e-voting as undertaken in the above mentioned pilot projects as well as the new

The original version of this chapter was revised: The copyright line was incorrect. This has been corrected. The Erratum to this chapter is available at DOI: 10.1007/978-3-540-44836-5_33

M.A. Wimmer (Ed.): KMGov 2003, LNAI 2645, pp. 274-284, 2003.

(C) Springer-Verlag Berlin Heidelberg 2003 
knowledge which was produced during the process. In doing so we indicate how knowledge management could be used to address major issues in e-voting such as security, data protection, transparency and social acceptance. Elections are a government initiated process providing citizens with a service. The product of this process is the electoral result. According to Coleman [Coleman et The Independent Commission of alternative voting methods, 2002] :

" The public can only be expected to have confidence in the electoral system if it is based upon transparently fair and robust procedures and working methods",

One of the major issues in the case of e-voting is therefore to gain public confidence in the process as well as its results. In simple terms, citizens and administrative staff must trust any new electoral process introduced. Appropriate knowledge management could provide all interested agents with a better understanding of the new e-voting processes.

This paper is based on the evaluation reports produced following the 2002 pilot projects. The UK 2002 e-voting pilots were the first to be followed by a systematic evaluation and description of the gained experience, where as most existing e-voting reports focus mainly on providing guidelines for future projects [CalTech MIT Voting Technology Project, 2001], [ OASIS Election and Voter Services Technical Committee].

We are aware of the vast literature on knowledge management and the equally varied definitions of the term. We use the following as our definition of the concept of knowledge management:

"the identification and analysis of available and required knowledge assets and knowledge asset related processes, and the subsequent planning and control of actions to develop both the assets and the processes so as to fulfill organizational objectives." [Macintosh, 1999]. These knowledge assets can reside in people's heads, in paper documents in filing cabinets, in electronic format, etc. In this paper we focus specially on those assets that have been explicit through knowledge embedded in documents. Dieng-Kuntz and Matta (2002) argue that one of the main objectives of knowledge management is to "improve relationships with the external world (such as customers, or privileged partners" we extend this to include citizens. This 'improvement in relationships' is why we are motivated to consider KM for e-voting.

\section{Knowledge Provided to and from the Voters}

Prospective voters had to be educated in the use of the newly offered voting channels such as touch screen kiosks, and all three forms of remote voting (internet voting, SMS text, touch tone telephony). The dissemination of passwords, personal identification numbers and voter registration numbers should be regarded as necessary information flow between the administration and citizens, as well as the promotion campaigns which preceded the pilots so as to raise awareness of the pilots actually being conducted and increase turnout 
There were indeed some cases in which one could identify some information management efforts. In Chorley [ The Electoral Commission Chorley Borough Council p.s.e. 1. 2002] a dedicated website was set up http://www.chorleyelections.co.uk .

It provided advice on how to vote, a full list of nominations, interactivity during the count - with results updated as they were announced. The website was linked to the Council's main site and although this pilot was in the area of electronic counting, which meant that citizens voted through the traditional or postal channels, the content of the website also explained the reasons for which the Council was undertaking the pilot scheme. In this case voter education was provided for, although voters did not actually themselves have to use any kind of new voting technology.

However this was not the case in pilots using only touch screen kiosk voting. In Stratford on Avon [ Electoral Commission, Stratford on Avon p.s.e.2002], there were no voter education efforts, although the same kiosks had been used in 2000 in the first pilot of its kind in the UK. Nevertheless the 2000 e-voting pilot was on a much smaller scale, therefore in the 2002 elections, voters who had never seen a piece of equipment were called upon to use it. This generated concerns among voters about not knowing who they had actually voted for. In Bolton [ Electoral Commission, Bolton Metropolitan Borough p.s.e. ,2002 ], where the same kiosks were used, roadshow demonstrations were organized, and administration staff were issued with a prompt sheet which was used to guide voters through the process. In Chester [ Electoral Commission, Chester City p.s.e., 2002] two demonstrations were held and an election website was set up giving details on the pilot and providing results the day after the elections. In contrast, in Newham [ Electoral Commission, London Borough of Newham p.s.e.,2002], the Council's website provided links to list of candidates, details of demonstration days, advanced voting locations and more importantly an online demonstration of the touch screen unit.

In Swindon [ Electoral Commission, Swindon Borough p.s.e,2002 ], although the scheme included a multiplicity of new voting channels - including kiosk, internet voting and telephone voting - no voter education was provided in a smart form, a lack covered by the use of a help-line and a helpdesk. In St. Albans [Electoral Commission, St. Albans City and District p.s.e.,2002] a comprehensive educational programme was undertaken including a frequently asked questions page on the voting website, and the production and dissemination of a CD-ROM with video and demonstration of the use of new voting methods. In Crewe [ Electoral Commission, Crewe and Nantwich p.s.e.,2002] although the pilot was contracted to the same vendors as St.Albans' - BT and Oracle - no similar effort was undertaken. In Liverpool and Sheffield [ Electoral Commission, Liverpool City p.s.e. 2002 ] [Electoral Commission, Sheffield City p.s.e. 2002 ], a common approach was used probably because of the use of the same contractors BT-Election.com -. The voting website provided a frequently asked questions page and in both cases a special website was created, targeting young voters providing demonstration of the use of new voting channels using graphics to do so. The Liverpool young voter site http://www.voteeasyliverpool.co.uk reviewed Nov. 2002) is still active six months after the scheme providing the same context and demonstrations to those potentially interested, therefore contributing to further education of prospective voters.

${ }^{1}$ pilot scheme evaluation 
Out of the above comparison of practices followed, one can identify the diversity of different approaches. The aim of future research should focus on the effectiveness of each approach and the introduction of best practice guidelines.There is an apparent need for accumulating and managing all the knowledge that a prospective voter may need to :

- Use all new voting channels - technologies - effectively

- Understand the new processes well enough to trust their result

One major input in such an effort is voter feedback. In the case of the recent pilots in question, voters' views on the new methods of voting were gathered by traditional opinion survey methodologies such as exit polls, interviews, mailed questionnaires,

voter comments recorded by help-line operators, a telephone survey conducted by NOP [NOP ,2002 ] on behalf of the Electoral Commission. Only in the cases of Swindon and Crewe were the voters given the opportunity to fill in an on-line questionnaire.

\section{Knowledge Provided to and from Administration Staff}

By the term administration staff we mean the Returning Officers, polling clerks, counting staff paid by the local authorities and in general all local authority personnel involved in any stage of conducting the pilots. In all cases where any kind of machinery was used, which administrative staff had to operate (like counting equipment of paper ballots) or instruct voters on how to use (like touch screen kiosks) some training was provided by the technology providers. In Westminster [ Electoral Commission, Westminster City p.s.e., 2002] a counting center handbook was produced and in Chester a manual was provided to assist polling staff in the use and processes of operating the touch screen kiosk.

In all evaluation reports surveyed there is no mention of any kind of knowledge gathering from the administrative staff other than anecdotal data. In this case there is an obvious lack of a system to record any experience gained by the staff who operated the voting technology. This in turn prolongs the dependence of local authorities on technology providers and deprives any future staff training exercises of learning based on colleague experience.

\section{Knowledge Provided to and from Local Authorities}

Regarding the dissemination of results as a procedural information flow towards all interested parties (citizens, candidates, media, political parties) at the end of every electoral process, the main knowledge that local authorities had to offer was their accumulated experience in traditional elections. Nevertheless this was neither structured nor documented knowledge and it was mainly up to experienced staff members to provide their expertise to the project management of the pilots. While this formula provided acceptable results again this was limited to formal and informal consultation rather than organized knowledge management.

However a greater issue arises when looking into the knowledge that was actually provided from the technology providers to the local authorities. In all cases except 
Broxbourne [Electoral Commission, Broxbourne Borough p.s.e. 2002 ] the technology used was provided by an external commercial technology vendor. Although the technology providers engaged their own staff in working along with the administration staff during the whole conduct of the pilots, that does not necessarily mean that the local authorities had a full understanding of how the technology performed the tasks in question whether that be counting, casting the vote or transmitting the data from remote voting to secure data bases. It was therefore due to trust from the local authorities towards the technology providers that it was possible to conduct these pilot projects as was indicated in the Electoral Commissions' general report on the pilots [ Modernising Elections 2002 ]. This issue will be further discussed in the transparency section later on .

\section{Security and Data Protection}

Security and data protection are closely related to the specific kind of technology used in each e-voting pilot. The following table aims to facilitate the reader's understanding.

Table 1. Technology used in each of the UK e-voting pilots (source DTLR )

\begin{tabular}{|l|l|l|l|l|l|}
\hline & $\begin{array}{l}\text { Touch-screen } \\
\text { kiosk }\end{array}$ & Internet & $\begin{array}{l}\text { Touch Tone } \\
\text { Telephony }\end{array}$ & SMS Text & e-count \\
\hline Bolton & $*$ & & & & $*$ \\
\hline Broxbourne & & & & & $*$ \\
\hline Chester & $*$ & & & & $*$ \\
\hline Chorley & & & & & $*$ \\
\hline Crewe & & $*$ & & & $*$ \\
\hline $\begin{array}{l}\text { Epping } \\
\text { Forrest }\end{array}$ & & & & & $*$ \\
\hline Hackney & & & & $*$ & $*$ \\
\hline Liverpool & & $*$ & $*$ & & $*$ \\
\hline Newham & $*$ & & & & $*$ \\
\hline Rugby & & & & & $*$ \\
\hline St Albans & $*$ & $*$ & $*$ & & $*$ \\
\hline S. Tyneside & & & & & \\
\hline Sheffield & $*$ & $*$ & & & $*$ \\
\hline Stratford & $*$ & $*$ & $*$ & & $*$ \\
\hline Swindon & & & & & \\
\hline Westminster & & & & & \\
\hline
\end{tabular}

In the cases of Westminster and Rugby where the same supplier was contracted [Electoral Commission Westminster p.s.e. 2002, Electoral Commission Rugby p.s.e. 2002 ] each stage of the vote counting process could be accessed only by authorized staff after scanning a bar coded identity card. Data was stored in an SQL server database regulated by two administrators each holding a 12 character password. The database itself was password protected and a report was run before the start of the count to ensure that there were no pre-loaded votes. However no precaution was taken against access through a default ID created at the time of the installation of the operating system. In Broxbourne [ Electoral Commission, Broxebourne p.s.e. 2002] the ballot papers contained a bar code against each candidate's name which was later 
scanned and logged into a database. Access to the counted votes was allowed to two officials who theoretically could alter the votes with their actions being nevertheless logged. However this process was never conducted and all operators of the system used the same user ID not allowing tractability of their actions.

In Epping Forrest [Electoral Commission Epping Forrest p.s.e. 2002 ], South Tyneside [ Electoral Commission S. Tyneside p.s.e. 2002 ] and Chorley [Electoral Commission Chorley p.s.e. 2002] where the same counting machinery and result collating software were used, although the software allowed different levels of access to each user this feature was not used. In Stratford [Electoral Commission, Stratford on Avon p.s.e. 2002 ] and Bolton [ Electoral Commission, Bolton p.s.e. 2002 ] where the same touch-screen voting kiosk was used the data was automatically recorded on a module and later kept for six months to provide an audit trail ; the data on each module were protected and once stored then could not be altered. As the module should be physically detached from the kiosk and transferred to the counting centers physical security was also needed. In the case of Stratford a virtual private network was used to transfer the final results to the Council's intranet. The kiosk used in Chester [ Electoral Commission, Chester p.s.e. 2002] and Newham [ Electoral Commission, Newham p.s.e. 2002] had a triple data recording system. Each vote was recorded in the machine's flash memory, and to data cartridge and at the end of the vote a print out audit was produced. The merged table - containing the results of all cartridges - was locked to prevent any alterations of the produced results. In the case of Newham three administrators had access rights and another three had "superuser" access rights but the system required two of them being present simultaneously for any changes to be made.

In Swindon [ Electoral Commission, Swindon p.s.e. 2002] all voters were provided with 10 digit PINs (personal identification numbers) but a date of birth was also required to allow remote voting. Once the vote was cast it was encrypted and stored in a secure server. The vote was transferred through a secure sockets layer (SSL) system to avoid tampering with the vote until stored to the server (similar to standard ecommerce practice ). Data files were date stamped however no encryption was provided over telephone voting and there was no check whatsoever that the technical supplier had recorded the votes correctly.

In St.Albans [Electoral Commission, St.Albans p.s.e. 2002] and Crewe [ Electoral Commission, Crewe and Nantwich p.s.e. 2002] voters were issued separately with a 4 digit PIN and a 16 digit VIN (voter identification number) for remote voting. The votes as well as voter information were encrypted and passwords to the UNIX servers were issued to the supplier's staff although different people had access to their relevant part of the software. Firewall and intrusion software was in place and server penetration testing was applied.

A different approach was used in Liverpool \{Electoral Commission, Liverpool p.s.e. 2002] and Sheffield [Electoral Commission, Sheffield p.s.e. 2002]. All voters were issued with 6 digit VRNs (voter reference numbers), 8 digit Pins and 10 digit passwords all delivered in the same instance - possibly reducing the security effectiveness of the PIN. Other than that the same security measures were taken as above (standard e-commerce technology), BT being a partner in all four supplier combinations although we cannot be sure about data base security as it was handled by a different supplier (election .com) for which no specifications were given in all the evaluation reports reviewed. 


\section{Transparency and Social Acceptance}

The Representation of the People Act requires that votes cast in UK elections should be traceable, but only in the event of legal challenges to the outcome, for example where there are allegations of malpractice[ www.uk-legislation.hmso.gov.uk/acts].

Bearing in mind the above is essential for understanding the context in which the 2002 UK e-voting pilots were devised. We should also make the distinction between the transparency of operation of a process and the transparency of the knowledge that this process produces. In this case the process would be casting the vote or counting the votes cast and the knowledge produced out of this is twofold:

- How was the result produced (the result itself being a data flow )

- Who voted for whom (referring to the possible mishandling of data relating each voter to the candidate of his/her choice for purposes other than judicial )

A further issue to address is the dependence of social acceptance on transparency regarding the first, and understanding of safeguards to protect the second.

In the case of Westminster there were voter concerns about asking them not to fold their ballots - in order to facilitate the electronic counting - as this would undermine the secrecy of their choice. People complained about being too far from the actual place where the counting took place and it was suggested that the bar code on the ballot paper could link it to the voter. Nevertheless this was not the case since the system used had no details of which voter the ballot paper was issued to. Therefore only the local authority had access to that data and only after combining it with voter registration records. Being unable to observe individual ballots was also the case in Hackney. In the cases of S. Tyneside, Epping Forrest and Chorley, trust in the system of counting was developed through demonstration and testing of the machinery and adjudication took place later on for contested ballots. In the cases of Stratford on Avon and Bolton votes were recorded on modules therefore no physical evidence of the votes cast existed. In Bolton trust was gained through demonstration and past use of the kiosk in other elections in the Netherlands and Germany. However in this case too there was no possible connection between the voter and his/her vote as authentication of the voter's identity was done in the traditional way by polling clerks. The touch-screen kiosk used in Chester and Newham did not relate voters to their choice as authentication was done separately but produced a paper audit which increased the possibility of verification.

It is much more interesting though to address the same questions in the cases of remote voting. In Swindon [Electoral Commission, Swindon p.s.e. 2002 ] the commercial vendor never got to know which PIN related to each voter as the PINs once created were sent to the local authority to attribute to each voter on the register. Vice versa the local authority had no log of the votes cast nor an understanding of how the records were created but only trusted the commercial vendor of fulfilling his part of the deal. In this case voter anonymity was preserved but knowledge of how the result was produced was not transparent. In the cases of St.Albans [Electoral Commission, St.Albans p.s.e. 2002 ] and Crewe [ Electoral Commission, Crewe and Nantwich p.s.e. 2002] neither the process of producing the result was transparent nor voter anonymity was preserved as the database administrators had access to the full data of voters as well as their voting choices, the administrators themselves being employees of the commercial suppliers and not local authority staff. Maybe it is worth mentioning that the commercial suppliers were funded with $£ 1 \mathrm{~m}$ by the DTLR 
(Department of Transport, Local government and the Regions.) although the commercial rights to the application remained with the suppliers.

A pattern similar to the one followed in Swindon was followed in Liverpool and Sheffield [ Electoral Commission, Liverpool p.s.e. 2002 ] [ Electoral Commission, Sheffield p.s.e. 2002] . The commercial vendor provided the local authorities with VRNs and in turn these were matched by the local authority to the register. Neither the commercial partner knew the details of the voter related to each VRN, nor did the local authorities know each voter's PIN and password. However the two sets of data were put together on one occasion in order to print the voter polling cards thus creating a record which could relate voters to their choice. The process of producing the result was not transparent nor understandable to all interested parties as the software source code was not open to scrutiny. Testing prior to the official use was conducted to cover for this lack of transparency and improve local authority and candidate trust in the system.

The NOP report clearly indicates that the major obstacle that e-voting has to overcome to gain social acceptance is the voter reservations on the issue of security and fraud [ Public opinion in the pilots, 2002]. According to the assessment of the ICAVMZ[ [Electoral Reform Society 2002] :

' Scrutiny of the voting and the counting processes is not possible with remote online voting to nearly the extent that is possible under the current system. Many of the processes are just not visible in the same way'

It is therefore necessary to promote public awareness of the safeguards in place [ Electoral Commission, Modernizing elections, 2002] .

In Swindon a special reference is made in the Commission's report regarding the Deputy Returning Officer and the acceptance that the project gained due to his good leadership. That can also be related to the results of the Council's on-line survey giving high user confidence in the system.

\section{Discussion}

Out of all the above it is quite evident that local authorities and, in prospective scalable pilots, even larger government organizations, are dependent on the expert knowledge of external commercial technology suppliers. There are however certain issues to be addressed ; the source code of systems is one of them. According to the ICAVM :

'What is clear is that the source code of the system must be made available on an official basis to those who have the qualifications to ascertain just how secure the program really is "

Co-operating on an equal basis with the technology suppliers is one thing while being totally dependent on them - as were most of the local authorities in the examined pilots - is quite another. The legal responsibility for conducting the election remains with the local authority and therefore those in office assume legal accountability as well .

The issue of managing new forms of knowledge is also a matter of great importance.

${ }^{2}$ Independent Commission on Alternative Voting Methods 
In the case of e-voting, an electronic vote audit trail positioned in the hands of commercial vendors, relating voters to their choice, cannot simply be regarded as a set of data. Knowing who voted for whom is valuable knowledge for political parties, candidates, political analysts, political marketing experts, certain parts of the media (how famous people cast their vote ), political activists and any agent with a genuine interest in the outcome of elections. It is therefore rather unethical to trust personal data produced through state administrated processes to commercial suppliers and in general any kind of organization working for financial profit.

The same could be said not only about voter trails but any kind of government produced personal data such as medical records from state hospitals or tax records.

The need is quite obvious ; to regulate the co-operation between technology suppliers and government organisations in the delivery of e-government processes. Furthermore user anonymity must be retained and the new knowledge produced should either be protected from unlawful use or used by accredited organisations to support government functions. The case of distributing disconnected knowledge to different agents seems to be a working solution. The idea of a third trusted party, an independent organization providing its expert knowledge as suggested by the ICAVM or a third party mirroring of the process seems to lead in the right direction.

\section{Conclusions}

From this analysis of the May 2002 UK Local Authority e-voting pilots, it is possible to identify the following areas of gained experience :

- In the case of electronic voting, regarded as a new e-government service [ Electoral Commission, Modernising Elections 2002 ] prospective users of the newly introduced technology, in this case voters, need to be properly educated in its use. In doing so, knowledge management can provide a comprehensive educational platform so as to convey user familiarity features in ways which will have the maximum effect to the largest number of people. Such efforts should be incorporated in a continuous citizen education planning. It is therefore impossible to do so in the pilot phase of e-voting as strategic decisions have to be made upon which technologies will be followed prior to planning a long term citizen-voter education program.

- The knowledge acquired through the opinion surveys, which was based on after voting experiences of voters who used the new voting channels, can provide invaluable experience in the design and implementation of new e-voting pilots. Up to now, no such effort to organize and structure the voter surveys has been identified.

- The knowledge acquired by the local authority administration staff during these pilots and the experience gained can also provide a comprehensive understanding of what local authorities can expect in future pilots, and educate staff to be used in future electronically enabled elections. Up to now, no such effort to organize and structure the administration staff's knowledge has been identified.

- Local authorities need access to the set of knowledge that commercial suppliers will not provide, in order to be able to audit the process efficiently. If commercial 
suppliers do not conform to the ICAVM guidelines about source code being open to scrutiny, using commercial confidentiality reasons, then a knowledge management system under the audit of a third specialized agent would be a first solution.

- Although security and data protection are related to the technology used, the ways of conveying their existence and effectiveness to all interested agents is crucial to the progress of electronic voting.

- Transparency of all procedures, is essential in the implementation of e-government applications especially when the traditional process to be substituted involves a high level of transparency and the ability of the public to scrutinize.

- The greatest risk in the social acceptance of e-voting is the voters' understanding about the security provided and the possibility of fraud and malpractice within the new voting applications. Misunderstanding and total lack of knowledge about the safeguards provided in a process, provide a further area for organized conveying of knowledge not only to voters but also to non-voters (users- non users) .

- There is an ethical issue in the matter of trusting non-government agents (commercial partners) with sets of data produced during an e-government process, which could provide knowledge on user preferences (who did one vote for) to non intended third parties. The practice of mirroring processes owned by commercial partners and dividing related data to distributed agents can minimize that risk.

This paper has presented some major issues of knowledge management implications in the field of e-voting. We should however note that as elections are a government motivated process, core e-government applications can benefit from the understanding of all accumulated knowledge gained in the field of e-voting. Further pilots and more over their subsequent evaluation can provide an invaluable resource to this end.

Acknowledgements. We are grateful for the support of ITC staff in critiquing this paper. Particular thanks go to John Fraser and Angus Whyte.

\section{References}

1. Dieng-Kuntz, R., and Matta, N. Knowledge Management and Organizational Memories; published by Kluwer Academic Press; 2002

2. HM Government. (2002) In the Service of Democracy - a consultation paper on a policy for electronic democracy. Published by the Office of the e-Envoy, Cabinet Office, London.

3. Macintosh, A., I. Filby and J. Kingston, Knowledge Management Techniques: Teaching \& Dissemination Concepts. International Journal of Human Computer Studies (Special Issue on Organizational Memories \& Knowledge Management), vol. 51, no. 3, Academic Press, September 1999.

4. The Electoral Commission, pilot scheme evaluation Bolton Metropolitan Borough 2 May 2002, 2002

5. The Electoral Commission, pilot scheme evaluation Broxbourne Borough Council 2 May 2002, 2002

\footnotetext{
${ }^{3}$ Independent Commission on Alternative Voting Methods
} 
6. The Electoral Commission, pilot scheme evaluation Chester City Council 2 May 2002, 2002

7. The Electoral Commission, pilot scheme evaluation Chorley Borough Council 2 May 2002, 2002

8. The Electoral Commission, pilot scheme evaluation Crewe and Nantwich Borough Council 2 May 2002, 2002

9. The Electoral Commission, pilot scheme evaluation Epping Forrest District Council 2 May 2002, 2002

10. The Electoral Commission, pilot scheme evaluation Hackney Council 2 May 2002, 2002

11. The Electoral Commission, pilot scheme evaluation Liverpool City Council 2 May 2002, 2002

12. The Electoral Commission, pilot scheme evaluation London Borough of Newham 2 May 2002, 2002

13. The Electoral Commission, pilot scheme evaluation Rugby Borough Council 2 May 2002, 2002

14. The Electoral Commission, pilot scheme evaluation St Albans City and District Council 2 May 2002, 2002

15. The Electoral Commission, pilot scheme evaluation South Tyneside Metropolitan Borough Council 2 May 2002, 2002

16. The Electoral Commission, pilot scheme evaluation Sheffield City Council 2 May 2002, 2002

17. The Electoral Commission, pilot scheme evaluation Stratford on Avon District Council 2 May 2002, 2002

18. The Electoral Commission, pilot scheme evaluation Swindon Borough Council 2 May 2002, 2002

19. The Electoral Commission, pilot scheme evaluation Westminster City Council 2 May 2002, 2002

20. The Electoral Commission, Modernising Elections : A Strategic Evaluation Of the 2002 Electoral Pilot Schemes, 2002

21. Pratchett, L. " The implementation of electronic voting in the UK " LGA Publications, the Local Government Association, 2002

22. NOP World "Public Opinion In The Pilots 2002, A report summarizing the aggregate findings from surveys carried out by NOP Research in May 2002 In 13 electoral pilots scheme areas', 2002

23. Coleman, S. et Independent Commission on Alternative Voting Methods Elections on the $21^{\text {st }}$ Century: from paper ballot to e-voting Electoral Reform Society, 2002

24. Www.voteeasyliverpool.co.uk as reviewed Nov. 2002

25. CalTech MIT Voting Technology Project, Voting: What is, What Could Be , 2001

26. OASIS Election and Voter Services Technical Committee, Election Mark-up Language (EML): e-Voting Process and Data Requirements, 2002

27. www.edemocracy.gov.uk as reviewed Nov.2002

28. www.uk-legislation.hmso.gov.uk/acts as reviewed Nov.2002 